\title{
Congenital Dacryocystitis- Clinical Profile and Outcome
}

\author{
Kumar $\mathbf{K}^{1}$, Dubey $\mathbf{A}^{2}$, Borasi $\mathbf{S}^{3}$, Som $\mathbf{V}^{4}$ \\ ${ }^{1}$ Dr. Kavita Kumar, Department of Ophthalmology, Gandhi Medical College, Bhopal, ${ }^{2}$ Dr. Aditi Dubey, above two \\ author attached with Department of Ophthalmology, Gandhi Medical College, Bhopal, ${ }^{3}$ Dr. Saurabh Borasi, Department \\ of Health and Family Welfare, Bhopal, ${ }^{4}$ Dr. Vivek Som, Department of Ophthalmology, Gandhi Medical College, \\ Bhopal, MP, India.
}

Corresponding Author: Dr. Aditi Dubey, Assistant Professor, Department of Ophthalmology, $4^{\text {th }}$ floor Kamla Nehru Hospital, Gandhi Medical College, Bhopal (M.P.). Email: aditi.dubey1585@gmail.com

\begin{abstract}
Aim: To assess the clinical and epidemiological profile of congenital dacryocystis and its treatment outcome. Material and Methods: A prospective study was conducted for duration of two years, cases with congenital dacryocystitis of age less than 5 years were included. A detailed history was taken giving emphasis to epiphora onset, duration, treatment and resolution. Ocular examination was done along with regurgitation on pressure over lacrimal sac test. The plan for the management was standard stepwise approach according to age groups and clinical condition of the cases. The conservative treatment included sac massage and surgical procedure were probing and syringing and endonasal dacryocystorhinostomy. Follow-up was done for 6 months and final clinical assessment was done to assess the success of procedure. Results: Total 65 eyes of 51 cases were included in the study. Mean age of presentation was- $14.6 \pm 2.3$ months with 52.9\% females. Unilateral involvement was more common. Epiphora was most common complaint with $63 \%$ ROPLAS positive. The success rate of sac massage was $81 \%$ and the overall success rate for treatment of congenital dacryocystitis was $96 \%$. Conclusion: Congenital dacryocystitis is a common pediatric problem. Treatment of congenital dacryocystitis should be started as early as possible and in stepwise manner initially conservative than surgical.
\end{abstract}

Keywords: Congenital nasolacrimal, congenital dacryocystitis, Epiphora.

\section{Introduction}

Congenital nasolacrimal duct obstruction resulting in congenital dacrocystitis is present in $2 \%$ to $6 \%$ of newborns, however it resolves in the first 3 of 4 weeks in most of the infants [1-4]. Congenital dacryocystitis is due to delayed canalization of fibrous layer of the nasal mucoperiosteum and imperforate membrane, valve of Hasner at the lower end of the nasolacrimal duct. It is the last portion of the lacrimal drainage system to canalize, complete patency usually occur soon after birth [2].

Other conditions resulting in congenital nasolacrimal duct block includepresence of epithelial debris, membranous occlusion at its upper end near lacrimal sac, complete noncanalization and rarely bony occlusion [2,3]. Presence of obstruction in tear outflow leads to collection of tears in lacrimal sac. Patients with Congenital Dacryocystitis (also known as congenital

\footnotetext{
Manuscript received: $24^{\text {th }}$ July 2018

Reviewed: $4^{\text {th }}$ August 2018

Author Corrected: $10^{\text {th }}$ August 2018

Accepted for Publication: $14^{\text {th }}$ August 2018
}

nasolacrimal duct obstruction) usually presents with Epiphora, matting of eye lashes, swelling over sac area, mucopurulent discharge,regurgitation on pressure over lacrimal sac (ROPLAS) test positive and Secondary infection resulting in acuteacryocystitis [5]. Only $2.9 \%$ cases develop acute dacryocystitis [6].

Epiphora affects approximately $20 \%$ of neonates, but spontaneous resolution occurs in $96 \%$ of cases within the first 12 months [7]. The treatment modalities for congenital dacryocystitis are based on two basic principles - restoration of the natural nasolacrimal passage or by creating a fistulous tract between the lacrimal and nasal mucosa.

Sac massage (Crigler massage) and probing syring in gare the mainstays of treatment to restore the natural nasolacrimal passage, by perforating a persistent membranous obstruction at the distal end of the nasolacrimal duct. Conservative management of the newborn with a properly performed Crigler massage is 
appropriate however; the presence of a congenital dacryocystocele or the occurrence of acute and persistent dacryocystitis may require early and more aggressive therapy. The aim of the present study is to assess the clinical and epidemiological profile of congenital dacryocystis and its treatment outcome.

\section{Material and Methods}

Place of Study: Gandhi Medical College and Hamidia Hospital, Bhopal

Type of Study: Prospective

\section{Sampling Methods: Convenience Sampling}

Sample Collection: Cases attending Out Patient and Inpatient department in Hospital

Inclusion Criteria: Cases of Congenital Dacryocystitis of age less than 5 years, those willing to participate

Exclusion Criteria: Cases of congenital dacryocystitis, age more than 5 years, not willing for participation, with punctal abnormalities, poor punctual apposition, reflex watering or any nasal pathology like deviated nasal septum

Stastical Methods: The data was recorded on a predesigned performa and managed on a spread sheet (EXCEL; MICROSOFT CORP, REDMOND, WA). Statistical test for significance is applied using SPSS software to the variables studied and a $\mathrm{p} \leq 0.05$ were considered statistically significant.

This prospective study was conducted in the Department of Ophthalmology at a tertiary care hospital in central India. Approval from the local Ethics Committee was obtained. The study adhered to the tenets of declaration of Helsinki.

The cases with congenital dacryocystitis attending ophthalmology OPD for duration of two years January 2015December 2016, of age less than 5 years those willing to participate were included in the study.

Those with punctal abnormalities, poor punctual apposition, reflex watering or any nasal pathology like deviated nasal septum were excluded.Special emphasis was given to history of onset, duration and severity of epiphora. Prenatal, birth history and positive family history were recorded. A detailed ocular examination was done and any lesion if present was evaluated accordingly.

Emphasis was given to presence of telecanthus, epicanthal fold, and status of lacuslacrimalis whether dry or wet. Swelling in the lacrimal fossa region and ROPLAS test (regurgitation on pressure over lacrimal sac) to assess the patency of nasolacrimal duct. ENT examination to rule out nasal pathologies was also done.

The plan for the management was standard stepwise approach according to age groups and clinical condition of the cases (Table 1). Follow-up was done for 6 months. The conservative treatment included sac massage, with antibiotic eye drop instillation to prevent and treat any secondary infection.

The patients aged below 2 years of age with no history of any treatment/no history of sac massage/ history of failed sac massage were subjected to sac massage antibiotic eye drop instillation as primary treatment. Followed up for next 2 months in every 15 days and the clinical assessment was done for the success of procedure.

If there was no improvement in the symptoms then patient may proceed for the next treatment step i.e. surgical.

The surgical treatment was by probing\& syringing or by endonasal dacryocystorhinostomy. Symptomatic relief in epiphora, sac swelling and negative ROPLAS were taken as indicators for success of treatment.On the basis of success rate of the different procedure, outcome of the study was calculated.

The data was recorded on a predesigned performa and managed on a spreadsheet (Excel; Microsoft Corp, Redmond, WA). Statistical test for significance is applied to the variables studied and a $p \leq 0.05$ were considered statistically significant. 
Table-1: Treatment protocol in the study group.

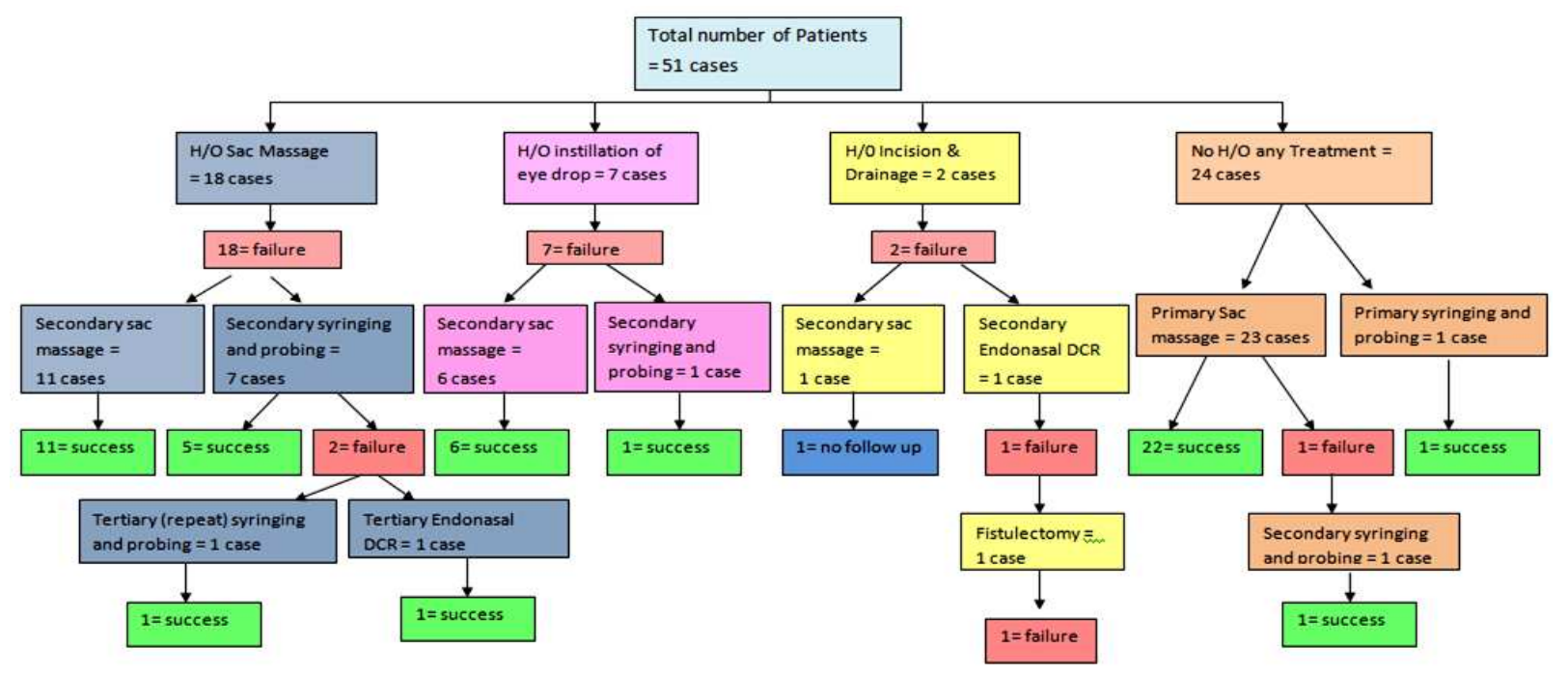

\section{Results}

Total 65 eyes of 51 cases fulfilling the inclusion criteria were included in the study. Most of the patients were in age group 2-6 months 35\%. Mean age of presentation was- $14.6 \pm 2.3$ months with $52.9 \%$ females (Table 2). Most of the cases $92 \%$ had history of full term delivery and 80 had history of normal vaginal delivery. Low birth weight cases were $19 \%$ and $12 \%$ cases had history of perinatal complication and hospitalization. Hemifacial paralysis and Atrial septal defect were the only systemic congenital anomalies present seen in $4 \%$ cases. Family history of congenital dacryocystitis or similar complaints was seen only in 1 case. There was no significant association of any of these factors with congenital dacryocystitis.

Table-2: Demographic Profile.

\begin{tabular}{|c|c|c|}
\hline Agewise distribution & No of cases $(\mathrm{n}=51)$ & Percentage (\%) \\
\hline $0-2$ months & 6 & 12 \\
\hline $2-6$ months & 18 & 20 \\
\hline $6-12$ months & 10 & 8 \\
\hline $12-18$ months & 4 & 6 \\
\hline $18-24$ months & 3 & 2 \\
\hline $2-3$ years & 1 & 17 \\
\hline $3-5$ years & 9 & 53 \\
\hline Genderwise distribution & & 47 \\
\hline Female & 27 & 72 \\
\hline Male & 24 & 27 \\
\hline Residential area & 37 & 14 \\
\hline Urban & 14 & 86 \\
\hline Rural & & 0 \\
\hline Socioeconomic status & 7 & \\
\hline Lower class & 0 & \\
\hline Middle class & & \\
\hline Upper class & & \\
\hline
\end{tabular}

Females were significantly more affected than male. Most of the cases $72.5 \%$ had unilateral disease. Unilateral involvement was 2.64 times more than bilateral involvement. Right eye was 1.31 times more affected as compare to left eye, which was statistically significant. Most of the cases in our series $72.5 \%$ were from urban area and $86.2 \%$ belonged to the middle class according to Kuppuswami classification (Table $2 \& 3$ ). 
Table-3: Clinical profile.

\begin{tabular}{|c|c|c|}
\hline Perinatal history & & \\
\hline Full term delivery & 47 & 92 \\
\hline Preterm delivery & 4 & 8 \\
\hline Normal vaginal delivery & 41 & 80 \\
\hline LSCS & 10 & 20 \\
\hline Preterm (<37 weeks) & 4 & 8 \\
\hline Low birth weight $(<2.5 \mathrm{~kg})$ & 10 & 20 \\
\hline Antenatal/natal/postnatal Complication and hospitalization & 6 & 12 \\
\hline Family history of Congenital dacryocystitis & 2 & 4 \\
\hline Other systemic disease (hemifacial paralysis, ASD) & 2 & 4 \\
\hline \multicolumn{3}{|l|}{ Laterality } \\
\hline Unilateral & 37 & 73 \\
\hline Bilateral & 14 & 27 \\
\hline \multicolumn{3}{|l|}{ Dexterity } \\
\hline Left Eye & 16 & 31 \\
\hline Right eye & 21 & 57 \\
\hline \multicolumn{3}{|l|}{ Ocular symptomatology } \\
\hline Epiphora & 31 & 60 \\
\hline Epiphora with Discharge & 20 & 39 \\
\hline Conjunctival congestion & 3 & 6 \\
\hline \multicolumn{3}{|l|}{ Ocular signs } \\
\hline Punctal stenosis & 2 & 4 \\
\hline Fistula & 1 & 2 \\
\hline Swelling over sac area & 20 & 39 \\
\hline ROPLAStest & 32 & 63 \\
\hline
\end{tabular}

The most common presenting complaint was epiphora in $61 \%$ cases followed by swelling over sac area $39 \%$, epiphora with discharge $31 \%$, conjunctival congestion $6 \%$. On examination $63 \%$ cases had positive ROPLAS test, of which $94 \%$ had mucoid regurgitate and rest had mucopurulent.

\section{Table-4: Treatment Outcome}

\begin{tabular}{|c|c|c|c|}
\hline Procedure & Number of eyes & Outcome & Percentage $(\%)$ \\
\hline \multirow{3}{*}{ Sac massage } & \multirow{3}{*}{48} & 39- success & 81 \\
\hline & & 8- failure & 17 \\
\hline & & 1- no follow up & 2 \\
\hline \multirow{2}{*}{ Syringing and probing } & \multirow{2}{*}{10} & 9- success & 90 \\
\hline & & 1- failure & 10 \\
\hline \multirow{2}{*}{ Endonasal DCR } & \multirow{2}{*}{2} & 1-Success & 50 \\
\hline & & 1-Failure & 50 \\
\hline \multicolumn{4}{|c|}{ Final Treatment Outcome } \\
\hline & Success & 49 & 96 \\
\hline & Failure & 1 & 2 \\
\hline & Lost during follow up & 1 & 2 \\
\hline
\end{tabular}

Treatment started in stepwise manner starts with sac massage then syringing and probing and then if both of these procedures fail endonasal DCR was done as stated in Table 1. The final outcome of different individual procedures were 
compared with each other and found that success rate of sac massage $(n=48)$ was $81 \%$ success rate of syringing and probing $(\mathrm{n}=10)$ was $90 \%$, success rate of endonasal DCR $(\mathrm{n}=2)$ was $50 \%$ and the overall success rate $(\mathrm{n}=51)$ of our treatment was $96 \%$ (Table 4). Final results of study show that; a stepwise standard operating protocol approach for management of congenital dacryocystitis has better and cost-effective outcome.

\section{Discussion}

Patients up-to 5 years of age were recruited for this study. Congenital dacryocystitis usually presented soon after birth or in first few weeks of life. In our study $66.67 \%$ cases presented within 1 year of life. The mean age of presentation was 14.64 months. Most of the cases were female. Similar results were also reported by many other authors [8-12]. The reason attributing for this can be the difference in anatomical and developmental factors of the lacrimal drainage system in male and female [8-13]. In current study unilateral involvement (72\%) was more than bilateral involvement $(27 \%)$ and right eye involvement (56\%) was more than left eye (31\%). Several other studies have they all found unilateral involvement was more than bilateral involvement [8-11]. In the present study right eye was more frequently involved. Similar result was reported by Bharadwaj et al [13].

However few study reported left eye frequently involving in congenital dacryo-cystitis $[8,14,15]$. In this study mode of delivery was normal vaginal delivery in $80 \%$ cases and $92 \%$ were full term. Congenital dacryocystitis is a developmental defect, so mode of delivery does not affect its occurrence. Family history is important to know the hereditary transmission. In the present series we could not find any significant hereditary association.

Most common complaintwasepiphora in $60.8 \%$ of cases and $32 \%$ had ROPLAS positive. No other significant ocular findings were noted. Bharadwaj et al reported $28 \%$ cases presented with epiphora and $72 \%$ cases had epiphora with discharge. Regurgitation test was positive in 79\% cases [13]. Results of these studies are different to our study; it might be due to subjective finding.

Treatment of the patients wad done in stepwise manner starting with sac massage then syringing \& probing and then endonasal DCR.A stepwise approach to the treatment of congenital dacryocystitis is a clinically and financially effective model for treatment [16]. The success rate for 48 cases treated by sac massage after 2 months follow up was $81 \%$. Several other studies also reported similar results and stated the effectiveness of sac massage in relieving congenital dacryocystitis in early age [16,17]. 11 cases with failed sac massage were restarted sac massage after proper demonstration of procedure and at the end of 6 months follow up, all 11 patients showed improvement. It indicates that proper sac massage method is also necessary for the success of sac massage. In the present study the success rate of sac massage significantly decreased with advancing age. It seems as the age progresses, the complex congenital dacryocystitis will develop which is difficult to cure by conservative management $[17,18]$. There was no significant difference in success of sac massage in any gender. At the end of 6 months follow up after syringing and probing, we found overall $90 \%$ success we found that, the success rate among different age groups; on chi-square test results were not significant.

In the present study it was used as secondary procedure but few authors have been advocated Probing as firstline management in patients aged $<1$ years of congenital dacryocystitis [19]. But majority stated that; there are no different to rates for spontaneous resolution up to 12 months of age, so they were in favour for wait and watch for spontaneous resolution [20-23].

Endonasal DCR was done in 2 cases in the present study. Both cases were done at age $>3.5$ years, and found overall success rate was $50 \%$. Because cases were less in endonasal DCR category so we can't comment on the results and outcome of the endonasal DCR.

Conclusion: Congenital dacryocystitis is a common pediatric ocular problem. Males and females are equally affected with unilateral presentation is common. Treatment of congenital dacryocystitis should be started as early as possible and in stepwise manner initially conservative than surgical. Now a day's early surgical intervention in form of syringing and probing is advocated by many authors as early as 6-9monts. In the current study we tried conservative approach of sac massage upto 2 years of age and found it effective. Proper method of sac massage should be taught and demonstrated to the care giver for better results. In conservative management the risk of surgery and harmful effect of anaesthetic agents can be avoided.

\section{References}

1. CASSADY JV. Dacryocystitis of infancy. Am J Ophthalmol. 1948 Jul; 31(7): 773-80; Disc, 875-7. 
2. GUERRY D 3rd, KENDIG EL Jr. Congenital impotency of the nasolacrimal duct. Arch Ophthal. 1948 Feb; 39 (2): 193-204.

3. Kushner BJ.Congenital nasolacrimal system obstruction. Arch Ophthalmol. 1982 Apr;100(4):597-600

4. Crigler L: The treatment of congenital dacryocystitis. JAMA 1923; 81:23-4.

5. Albert and jakobiec's ophthalmology- principle and practice of ophthalmology 3rd edition; February 12, 2008 volume-3; 3503-18.

6. Robb RM. Probing and irrigation for congenital nasolacrimal duct obstruction. Arch Ophthalmol. 1986 Mar; 104(3):378-9.

7. Jack J Kanski Brad Bowling- clinical ophthalmology a systematic approach - 7th edition; 2011; Elsevier Limited. 72-78

8. Aldahash FD, Al-Mubarak MF, Alenizi SH, Al-Faky YH. Risk factors for developing congenital nasolacrimal duct obstruction. DOI:10.1016/j.sjopt. 2013. 09.007

9. Shivpuri D, Puri A. Congenital nasolacrimal duct obstruction: the proper technique of massage. Indian Pediatr. 1994 Mar; 31(3): 337-40.

10. Kakizaki H, Takahashi Y, Kinoshita S, Shiraki K, I waki $\mathrm{M}$ The rate of symptomatic improvement of congenital nasolacrimal duct obstruction in Japanese infants treated with conservative management during the 1st year of age. Clin Ophthalmol. 2008; 2(2): 291-4.

11. Abrishami M, BagheriA,HosseinS S, Mirdehghan S. A. Late Probing for Congenital Nasolacrimal Duct Obstruction. J of Ophthalmic \& Vision Research 2009; 4 (2): 102-4.

12. Wang JC, Cunningham MJ. Congenital dacryocystocele: is there a familial predisposition? DOI:10.1016/j.ijporl.2010.11.026

13. Bhardwaj P, Singh K, Sharma K, Chalia D, Pal S. Lacrimal syringing versus combined lacrimal probing and syringing for treatment of congenital nasolacrimal duct obstruction in children. Int J Med Res Rev 2016;4 (6): 964-970.

14. Kim HC, Cho AR, Lew H. Dacryoscintigraphic findings in the children with tearing. DOI:10.3341/kjo. 2015.29.1.1

15. Cha SD, Lee H, Park M S, Lee J M, Baek S H. Clinical Outcomes of Initial and Repeated Nasolacrimal Duct Office-Based Probing for Congenital Nasolacrimal Duct Obstruction.Korean Journal of Ophthalmology 2010; 24(5):261-6

16. Casady DR, Meyer DR, Simon JW, et al. Stepwise treatment paradigm for congenital nasolacrimal duct obstruction.DOI:10.1097/01.iop.0000225750.25592.7f

17. Pediatric Eye Disease Investigator Group. Resolution of congenital nasolacrimal duct obstruction with nonsurgical management. DOI: 10.1001/ archophthalmol. 2012.454

18. Kakizaki H, Takahashi T, Kinoshita S, Shiraki K, Iwaki M. The rate of symptomatic improvement of congenital nasolacrimal duct obstruction in Japanese infants treated with conservative management during the first year of age. Clin Ophthalmol. 2008;2: 291-294.

19. Serin, Didem Buttanri, Ibrahim Bulent et alPrimary probing for congenital nasolacrimal duct obstruction with manually curved Bowman probes Clinical Ophthalmology. 2013;7:109-112

20. Kim YS, Moon SC, Yoo KW. Congenital nasolacrimal duct obstruction: irrigation or probing? DOI:10.3341/kjo.2000.14.2.90

21. Kashkouli MB, Kassaee A, TabatabaeeZ.Initial nasolacrimal duct probing in children under age 5: cure rate and factors affecting success. J AAPOS.2000; 6: 360-3.

22. Kashkouli MB, Beigi B, Parvaresh MM, et a. Late and very late initial probing for congenital nasolacrimal duct obstruction: what is the cause of failure? $\mathrm{Br} \mathrm{J}$ Ophthalmol. 2003 Sep;87(9):1151-3.

23. Maheshwari R. Results of probing for congenital nasolacrimal duct obstruction in children older than 13 months of age. Indian J Ophthalmol. 2005 Mar;53 (1): 49-51.

\section{How to cite this article?}

Kumar K, Dubey A, Borasi S, Som V. Congenital Dacryocystitis- Clinical Profile and Outcome. Trop J Ophthalmol Otolaryngol.2018;3(3):21-26.doi:10.17511/jooo.2018.i03.03 